\title{
The Importance of Systemic Balance in Safeguarding Health: A Randomized Double-Blind Clinical Trial on VLDL, Triglycerides, Free T3, Leptin, Ghrelin, Cortisol and Visceral Adipose Tissue
}

\author{
Xanya Sofra ${ }^{1,2}$ (1) \\ ${ }^{1}$ New School for Social Research, New York City, NY, USA \\ ${ }^{2}$ City University of London, London, UK \\ Email: science@iellios.com
}

How to cite this paper: Sofra, X. (2020) The Importance of Systemic Balance in Safeguarding Health: A Randomized DoubleBlind Clinical Trial on VLDL, Triglycerides, Free T3, Leptin, Ghrelin, Cortisol and Visceral Adipose Tissue. Health, 12, 10671084.

https://doi.org/10.4236/health.2020.128078

Received: May 31, 2020

Accepted: August 25, 2020

Published: August 28, 2020

Copyright $\odot 2020$ by author(s) and Scientific Research Publishing Inc. This work is licensed under the Creative Commons Attribution International License (CC BY 4.0).

http://creativecommons.org/licenses/by/4.0/

\begin{abstract}
The purpose of this clinical trial was to delineate some of the negative consequences of high BMI on health and explore the possibility of a solution. We analysed the blood test results of nine overweight adults with sedentary lifestyles, and an average BMI of 32.23. Results revealed a statistically significant reduction of visceral adipose tissue, very-low density lipoprotein (VLDL), and triglycerides. Testosterone, leptin, IGF-1 and Free T3 increased within the normal range, juxtaposed by cortisol and ghrelin that declined, but without dipping into abnormality. These findings have important implications during the COVID-19 pandemic, where optimal immunity is deemed necessary in limiting susceptibility to the virus. Recent research indicates that weight gain often escalates vulnerability to respiratory track disturbances, cardiovascular disease (CVD) and diabetes. Consequently, pre-existing conditions increase COVID-19 mortality rates. CVD and diabetes emerge out of hormonal imbalances that involve Free T3, leptin, ghrelin, testosterone, and cortisol. Physical training is decidedly the most acclaimed solution, yet, the least implemented one, due to procrastination, or demoralization after investing constant exhaustive effort with no immediately visible physical change. COVID-19 confinement exacerbates the tendency for inactivity, and promotes stress-eating behaviours. Moreover, strenuous exercise, necessary for visceral fat reduction, results in a negative cortisol/testosterone relationship that provokes caloric consumption and inflammation. Offering an alternative to exercise that effectively improves health, boosts metabolism, and controls appetite,
\end{abstract}


may serve as a proactive, and preventive method that can safeguard health.

\section{Keywords}

VLDL, Triglycerides, Free T3, Leptin, Ghrelin, Cortisol and Visceral Adipose Tissue, COVID-19 Susceptibility

\section{Introduction}

Optimal health appears to be the best defence against all disease including viral infections. Excess adiposity, elevated lipids, and hormonal imbalance instigate systemic disintegration, stemming from accumulated inflammation, dyslipidemia, metabolic dysfunction, and insulin resistance. Obesity is associated with diabetes and respiratory problems which contribute significantly to the burden of respiratory diseases [1] [2]. There is a high correlation between visceral adiposity and cardiovascular disease [3] [4]. High body mass index (BMI) often provokes myocardial infarction, particularly in the presence of abnormally high triglycerides [5]. High BMI is a multiracial contributor to the prevalence of diabetes 2, characterized by excess very-low density lipoproteins (VLDL) among other factors [6] [7] [8]. Corona virus (COVID-19) morbidity rates have gone up to $88.1 \%$ among patients with a BMI over 25 [9]. A possible explanation for this adiposity/COVID-19 relationship is the virus' binding preference to angiotensin-converting enzyme 2 (ACE2) receptors. The ACE2 expression in fat tissue is higher than in other organs; therefore, overweight individuals have a multiplicity of ACE2 expressing cells that may foster an inviting affinity to the virus, facilitating infection. ACE2 expression increases with hypertension and diabetes, which explains the vulnerability to COVID-19 infection and eventual fatality, among these patients [10] [11].

Thyroid hormones modulate every component of the cardiovascular system necessary for normal cardiovascular development and function, highlighting a correlation between Free T3 abnormalities and cardiovascular disease CVD [12]. Diabetes mellitus (DM) and Thyroid dysfunction influence each other, dysregulating metabolism, and interfering with Free T3 secretion [13] [14].

Overabundance of triglycerides, transported by very low-density lipoprotein (VLDL), narrows the arteries by hardened plaque that prompts an upsurge of blood pressure, accelerating the risk of CVD [15]. A 15-year multi-provincial cohort study found that high VLDL cholesterol was a prominent contributor of coronary heart disease [16]. Upraised VLDL and triglyceride concentrations have been confirmed in both Type 1 and Type 2 diabetes mellitus [17].

Cortisol abnormalities are linked to both heart disease, and diabetic complications [18] [19]. Cushing's syndrome, defined by excess cortisol, is one of the leading determinants of CVD fatality rates [20]. Cortisol increase is associated with hyperphagia and dyslipidemia [21]. 
Toxicity that is inherent in visceral adiposity, overloads hepatic detoxification systems, promoting insulin and leptin resistance that overstate the action of ghrelin, one of the central stimulators of appetite, ultimately promoting increased caloric intake [22]. Ghrelin, is an orexigenic hormone that stimulates appetite. Research has shown that ghrelin-producing cells seem to be more abundant in pathologically obese patients [23]. A minor increase in leptin reduces appetite, downsizing overall fat mass. However, escalated levels of the anorexic hormone are often associated with leptin resistance, a condition linked to weight gain [24]. This reflects a defect in intracellular communications, compromising the transport of leptin signals across the blood-brain barrier (BBB). Simply put, leptin overabundance is ineffective unless the body can receive and utilize its signals [25]. Both leptin resistance derived from excess, and its opposite, low plasma leptin, increase appetite and vulnerability to diseases. Cardiovascular mortality is often associated with low plasma leptin, while obesity, one of the causes of CVD, is usually correlated with unutilized leptin overabundance, or leptin resistance [26]. All viral infections cause elevated cytokine-3 signalling expression which inhibits leptin signalling. This signalling interference promotes overeating, exacerbating visceral adiposity, which, as previously stated, may have an inviting affinity to the virus binding preference to ACE2 that is abundant in adipose tissue [27]. Leptin is involved in glucose metabolism, and the regulation of cholesteryl esters that are crucial in energy modulation [28] [29] [30]. Diabetic insulin resistance allows for high glucose concentrations in the blood; this is exploited by the virus' tendency to increase glucose metabolism leading to hyperinflammation and immune exhaustion [31].

Depleted cellular energy provokes immune dysfunction, inevitably promoting T-cells apoptosis, and overall cellular degradation [32]. Earlier research has indicated that SARS-Cov morbidity relies on disabling systemic alarms, and depleting ATP by provoking a "cytokine storm" oversecretion of proinflammatory cytokines, and upsurging the defensive overproduction of interferon type 1 (IFN-1) [33] [34]. Doctors on the ground report that the COVID-19 induced lung immunopathology is not triggered by the "viral load," but hyperinflammation that turns out to be lethal for the patient, as rapid multiplication of cytokines mobilize overdriven white blood cells to uncontrollably attack internal organs [35]. Some investigators have hypothesized that ATP replenishment will rectify the adverse effects of hyperinflammation, by providing the energy necessary for systemic repair [36]. This premise is supported by several research findings. COVID-19 inhibits the IFN-1 "alarm" response; this can be reversed by restoring ATP [37]. Energy depletion in the elderly evidences the highest COVID-19 fatality rate of $14.8 \%$ [38]. Aging instigates immune failure in secreting IFN-1 which may be related to ATP insufficiency [39]. Regular Exercise can increase ATP reinstating mitochondrial functioning [40]. Tobacco smokers are more susceptible to COVID-19 infection, possibly due to mitochondria decay inhibiting ATP output [41] [42]. Additionally, men have higher morbidity 
rates than women, potentially due to females' higher levels of oestrogens, which stabilize ATP production during inflammation and oxidative stress [43]. A complementary interpretation places the focus on the need to stabilize a system in disarray; this delineates the significance of balance which is the theoretical perspective founding the current clinical trial. From this frame of reference, it can be argued that hyperinflammation is sustained by misapplied ATP during an immune panic reaction to overpower incoming danger. ATP replenishment in an disturbed system, dysregulated by disease, could potentially exaggerate the overabundance of interferons, interleukins, and overall biological activity that eventually ravages the host. Current research on 150 COVID-19 patients confirms that mortality is due to virally driven hyperinflammation provoked by elevated ferritin, interleukin-6 (IL-6), and interferon- $\gamma$ inducible protein 10 . The interferons trigger cascades of antiviral activity, however, in the process they shut down host protein synthesis inducing cell death [44]. All these processes including the white blood cells attacking the host, are powered by cellular energy; therefore, it may be the systemic panic blindly turning its defences against itself, devastating the body, rather than the depletion of energy.

An examination of the clinical course, and risk factors for mortality of adult inpatients with COVID-19 in Wuhan, found that mortality rate was higher in aged patients with diabetes, or coronary heart disease, as a result of increased inflammation, toxicity, and immune dysregulation. Inflammation was demonstrated by the elevated alanine aminotransferase (ALT), and interleukin 6 protein (IL-6). A dysfunctional immune system was identified by the evidence of lymphopenia, the abnormally low level of lymphocytes in the blood, and leucocytosis that reflects a higher leukocyte count of white cells, the cells that end up lashing against the body during the hyperinflammatory state [45].

In conclusion, obesity, diabetes, CVD, respiratory disorders and COVID-19 appear to be interconnected by hyperinflammation, excess lipids, lipoproteins, and hormonal irregularities including metabolic disturbances, and disproportionate variances in leptin, ghrelin, and cortisol. Testosterone deficiency is also correlated with CVD and diabetes [46]. Clinical research has shown that a raise in inflammatory markers was accompanied by both free and total testosterone suppression, suggesting that perhaps the older males' higher mortality rates from COVID-19 may have been due to testosterone decline with age [47].

In the current study we focused on some of the common denominators that appear to bridge life-threatening medical conditions. Overeating, obesity and inflammation are the starting point of a process eventually evolving into appetite and hormonal dysregulations, complemented by excess lipids, and lipoproteins that prelude the emergence of diabetes, CVD and respiratory disease. All these conditions are known to ultimately increase COVID-19 mortality rates [48]. We used an alternative to exercise to explore visceral adiposity, skeletal muscle mass (SMM) increase, insulin growth factor-1 (IGF-1) levels, VLDL, triglycerides, Free T3, testosterone, cortisol, and the appetite controlling hormones leptin and 
ghrelin. The rationale and necessity of a method that bypasses regular exercise is multidetermined: 1) Extensive quarantine is the best measure to stop the rapid spread of COVID-19. However, lockdown restricts physical activity that is necessary to maintain an adequate health status. 2) Realistically, most overweight individuals avoid gym workouts due to body image concerns, or the subjectively herculean effort and energy expenditure required, along with the months-long persistence and patience necessary before being rewarded by a visible body transformation. 3) The fact that physical training promotes cardiorespiratory fitness (CRF) is verified by a number of studies and the statistically significant inverse relationship between CRF and all-cause mortality $(\mathrm{p}<0.05)$. There is also evidence that exercise improves immunity [49] [50] [51] [52]. However, excessive exercise is perceived by the body as a form of stress, and stimulates the release of cortisol that may cause tissue breakdown with overtraining. 4) Cortisol is involved in the conversion of protein to glucose, potentially predisposing older individuals to type II diabetes [53]. 5) Strenuous exercise, necessary to reduce visceral adipose tissue, is associated with a negative relationship between cortisol and testosterone. As cortisol increases, testosterone decreases provoking stress eating behaviours, and accumulated adiposity that offset the benefits of exercise [54]. 6) During overtraining muscle-derived IL-6 is released into the circulation in high amounts leading to increased inflammation [55]. 7) Recent research using this alternative to exercise procedure has shown a decrease in visceral fat, VLDL, and triglycerides, juxtaposed by an increase of Free T3, and skeletal muscle mass [56] [57]. 8) Goldspink et al. [58] used an earlier modified version of this method exploring gene expression in fast and slow muscle fibre phenotypes. The stimulation method resulted in rapid hypertrophy of adult skeletal muscle that reflected an increase of up to $250 \%$ in RNA content, associated with the repression of the fast, and the activation of the slow myosin heavy chain genes.

\section{Methodology}

We adopted a novel technology originally designed and built in London University and completed in the EU funded Business Innovation Centre after 27 years of empirical research. Its original boards were patented in 1983, when they were first invented. Technological notes with validity and reliability data were never published to maintain the confidentiality of the proprietary formulas on which the technology is based. It emits 24 voltage driven complex waveforms, each built out of 4000 sine frequencies into square unlimited resolution composites, with resultant frequencies that vary from $888 \mathrm{~Hz}$ to $50 \mathrm{~Hz}$. It has a maximum voltage of $25 \mathrm{~V}$ at $500 \Omega, 50 \mathrm{~V}$ at $2000 \Omega$, and $100 \mathrm{~V}$ at $10 \mathrm{~K} \Omega$. The current generated by the voltage/resistance Ohm's equation, is miniscule, and cannot be measured. The twelve lower frequency waveforms are organized on the left of the technology labelled "visceral fat and deeper muscle". The higher frequency waveforms are on the right side, designated as "skin toning, detoxification and superficial muscle". The waveform dials are controlled manually and can be 
combined to offer a variety of 8 secs full musculature contractions, repeated about 1000 times during the one hour treatment. The technology reaches the skin via 16 silver plated tour grade microphone cables connected to gel pads which are attached onto the body. It is hand-made in the UK, with no digital components to offer an unlimited resolution output. It is classified as IEC class I according to the IEC60601-1 standard, and is used with 3-pin din and 4-pin din IEC 60601-1 compliant cables. It has a CE marketing directive of Class I, with electromagnetic compatibility regulations applied standards EN50081-1 and EN50082-1. Additionally, it complies with the EEC UK directive of electrical equipment safety-applied standard IEC 60601-1 standard. Different versions of the technology have been used in clinical practice by over 5,430 physicians and aesthetic practitioners in the past twenty years, with no reported side effects. The only contraindication, according to the FDA, is having an implanted device like a pacemaker. The main cautions are pregnancy, and consultation with the patient's primary physician in case of a medical disorder. Adverse reactions are limited to temporary skin redness from the pads, which occurs sporadically, and usually dissipates within an hour. Earlier models of this technology, with the same hardware design, have been cleared by the FDA in 2012 (K132158) and 2013 (K123157) for muscle conditioning.

Additional measuring instruments included a conductance scale that calculated BMI, visceral adipose tissue and skeletal muscle mass and a blood test that investigated the subjects VLDL, triglycerides, cortisol, testosterone, Free T3, leptin and ghrelin.

\section{Procedure}

Nine adults, five females and four males, ages 35 - 49 years, with an average BMI of 32.23, participated and completed this fifteen treatments clinical trial that took place over a period of five weeks. Subjects were randomly selected out of a list of 14 eligible candidates, offered by five different clinics. The inclusion criteria were determined on the basis of a comprehensive health questionnaire completed by 18 subjects that agreed to undertake the treatment. Four subjects did not fulfil the inclusion criteria and were excluded: Inclusion criteria were: 1) Overweight or obese. 2) BMI over 28. 3) No experience with the technology. 4) Sedentary lifestyle for at least five years. 5) Had previously received laser and radiofrequency treatments with modest outcome and rebound results. 6) Not currently following a particular diet plan. 7) No operation or child birth for at least four months. Exclusion criteria were: 1) Pacemaker, or other implanted device. 2) Pregnancy, or trying to get pregnant. 3) Operation, or childbirth within the past four months. 4) Any medical or mental disorder, or condition other than obesity. 5) Prior experience with the technology-this term was important, to exclude subjects that could guess the study's hypotheses. 6) Engaging in regular exercise-this intended to control the study outcome, so that results were not influenced by the subjects' active lifestyle. 7) Following a strict diet with a dieti- 
cian-this exclusion criterion was adopted to eliminate the possibility that results were scewed by the subjects' diet.

Every precaution was taken to protect the subjects' privacy and the confidentiality of their personal information. Subjects were informed that they had the right to refuse participation at any time. All subjects were presented with the consent form, which they had to read thoroughly, and sign after confirming that they had clearly understood its contents. The subjects were not in a dependent relationship with the technology operators, the lab and measurement technicians, or the author. The subjects did not receive a specific diet, or instructions regarding changes in their lifestyles. There was no subject attrition.

The individuals appointed as clinical operators were given basic training on how to operate the technology, without disclosing the experimental hypotheses. None of the operators had a dependent relationship with the author. None of them had any known bias or any personal interest in the direction of the results.

Each participating clinic selected their own lab; therefore, five independent laboratories were assigned to take blood samples, before, and two weeks after completion of the fifteen one-hour treatments, that took place three times a week, for five weeks.

Subjects' sessions were arranged on different days, to avoid subjects' interaction. The clinical operators were prohibited from discussing their observations or opinions with each other. In case a subject had a side effect or adverse reaction, the clinical operators were instructed to contact the clinic's physician immediately. None of the subjects had any adverse reactions or reported side effects.

The scale measurements were performed in a separate room, by the independent technician who had no experience in the technology or conflicts of interests. They were done before the first treatment, and two weeks after the last treatment. The subjects did not receive any other procedure during the two weeks after their last treatment and until the measurements and blood tests were performed.

Following the initial blood tests and measurements, each subject went to their private treatment room, and lay on the massage bed, while the gel pads and cables from the 16 channels of the technology were attached onto his/her body by the clinical operator. The cables from ten of the channels were attached onto the gel pads of the waist and abdomen, and the cables from the six remaining channels were connected to the gel pads placed along the lymphatic system pathways of the legs and arms, to enhance detoxification during treatment.

All subjects gave a detailed report of their subjective experience immediately after all treatments were completed and two weeks later. The procedure was performed in accordance with the ethical standards and principles for medical research involving human subjects and was approved by the ethical boards of each clinic that supplied the study participants. 


\section{Results}

The data was analysed with the Analysis of Variance for repeated measures and T-tests for two dependent means. Table 1 shows the testosterone and cortisol fluctuations for each subject before and after treatments. Testosterone increase was statistically significant with a $\mathrm{T}=3.101333$, a $\mathrm{p}$ value of $\mathrm{p}=0.00732$ and a significance level of $\mathrm{p}<0.01$. For cortisol decrease the $\mathrm{T}$ value was $\mathrm{T}=-5.98 ; \mathrm{p}$ value was $\mathrm{p}=0.00017$. Cortisol significantly decreased at the $\mathrm{p}<0.001$ level.

Insulin growth factor-1 (IGF-1), skeletal muscle mass (SMM) leptin, and Free T3 significantly increased at a high statistical probability level. Visceral Adipose tissue, ghrelin, very-low-density lipoprotein (VLDL), and triglycerides showed a statistically significant decrease. Importantly, all hormonal fluctuations were within the normal range.

Table 2 reflects a body mass index (BMI) decrease of -5.79 and a highly statistically significant $\mathrm{t}=-10.94$ with a value of $\mathrm{p}<0.00001$. Table 2 also denotes a $16 \%$ increase of IGF-1, a statistically significant outcome with $t=7.607811$, a value of $\mathrm{p}=0.00003$ and a significance level of $\mathrm{p}<0.0001$. There was also an average $23.13 \%$ increase of SMM, with value of $t=12.66705$ and the value of $\mathrm{p}<$ 0.00001 raising the statistical significance level to $\mathrm{p}<0.00001$.

Table 3 displays a notable decrease in both VLDL and triglycerides that was significantly more robust than the results of most other variables both in terms of percentage and statistical significance level (Table 4). Trglycerides $t=$ -12.065904 and value of $\mathrm{p}<0.00001$ with a significance level of $\mathrm{p}<0.00001$. VLDL $\mathrm{t}=-14.042083$ with a value of $\mathrm{p}<0.00001$ and a significance level of $\mathrm{p}<$ 0.00001 .

Table 4 displays the results of the T-tests on all the variables tested.

Table 1. Blood Plasma Subjects' Results on Testosterone and Cortisol for each subject.

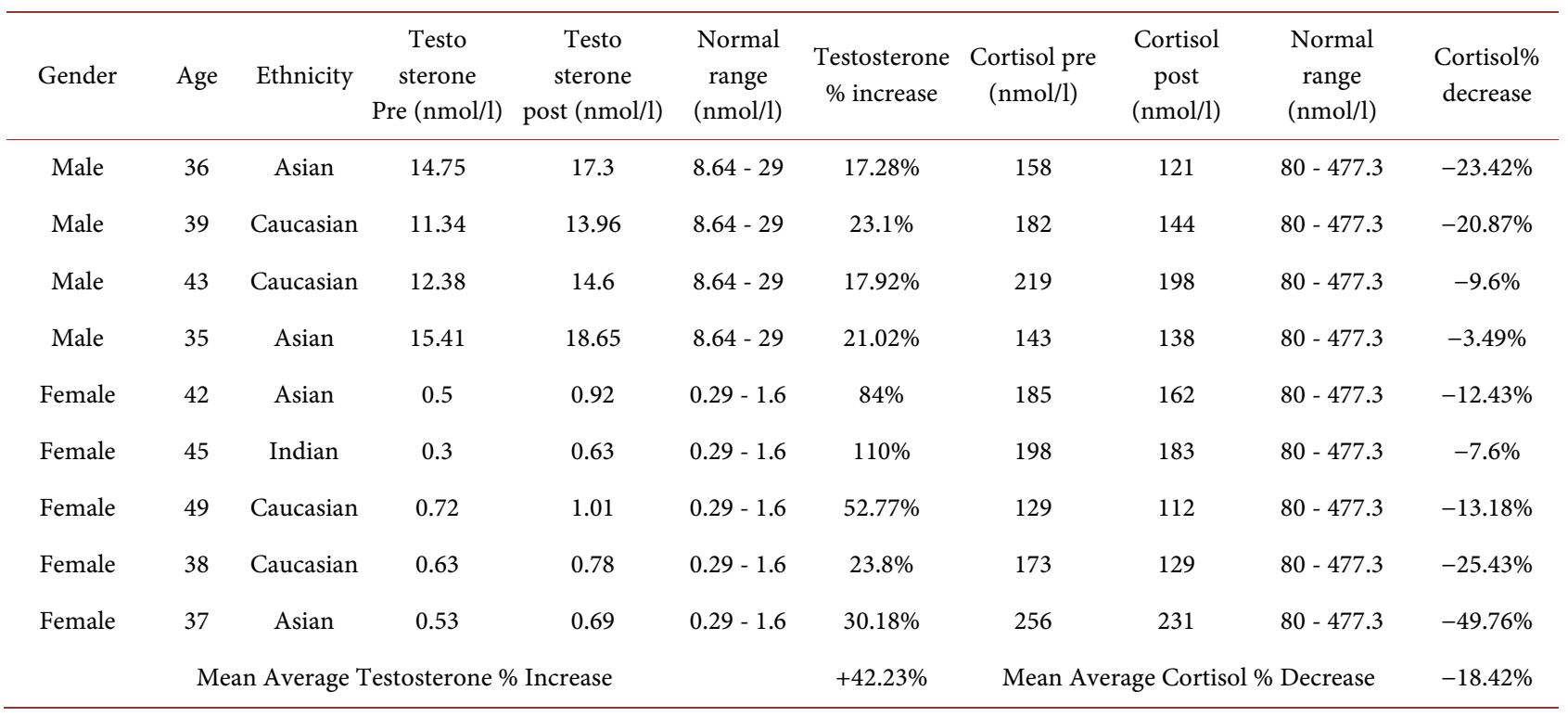

Both testosterone increase and cortisol decrease remained within the normal range. Testosterone overall increase was $+42.23 \%$. Testosterone showed a mean average increase of $+20.15 \%$ increase for males and a mean average of $+60.15 \%$ for females. Cortisol showed a mean average decrease of $-18.42 \%$. 
Table 2. BMI Reduction and Blood Plasma Subjects' Results on IGF-1 and Scale Results on SMM.

\begin{tabular}{|c|c|c|c|c|c|c|c|c|c|c|c|}
\hline Gender & Age & Ethnicity & $\begin{array}{l}\text { BMI } \\
\text { Pre }\end{array}$ & $\begin{array}{l}\text { BMI } \\
\text { Post }\end{array}$ & $\begin{array}{c}\text { IGF-1 } \\
\text { Pre } \\
\text { (nmol/1) }\end{array}$ & $\begin{array}{c}\text { IGF-1 } \\
\text { Post } \\
(\mathrm{nmol} / \mathrm{l})\end{array}$ & $\begin{array}{l}\text { Normal } \\
\text { range } \\
(\mathrm{nmol} / \mathrm{l})\end{array}$ & $\begin{array}{l}\text { IGF-1 \% } \\
\text { increase }\end{array}$ & $\begin{array}{l}\text { Skeletal muscle mass } \\
\text { (SMM) Pre }\end{array}$ & $\begin{array}{c}\text { Skeletal } \\
\text { muscle mass } \\
\text { (SMM) Post }\end{array}$ & $\begin{array}{c}\text { SMM } \\
\% \\
\text { increase }\end{array}$ \\
\hline Male & 36 & Asian & 29.7 & 25.7 & 22.93 & 24.75 & $15.08-32.5$ & $7.93 \%$ & 27.65 & 30.87 & $11.64 \%$ \\
\hline Male & 39 & Caucasian & 33.3 & 26.9 & 27.16 & 30.06 & $15.08-32.5$ & $10.67 \%$ & 33.30 & 39.60 & $18.91 \%$ \\
\hline Male & 43 & Caucasian & 34.2 & 27.3 & 29.97 & 31.96 & $15.08-32.5$ & $6.63 \%$ & 36.40 & 39.80 & $9.34 \%$ \\
\hline Male & 35 & Asian & 32.8 & 26.4 & 24.33 & 26.75 & $15.08-32.5$ & $9.04 \%$ & 27.13 & 31.95 & $17.75 \%$ \\
\hline Female & 42 & Asian & 29.6 & 25.9 & 18.55 & 24.37 & $11.25-28.8$ & $23.88 \%$ & 17.57 & 23.32 & $32.72 \%$ \\
\hline Female & 45 & Indian & 35.2 & 27.4 & 23.76 & 27.94 & $11.25-28.8$ & $17.59 \%$ & 20.16 & 24.53 & $21.67 \%$ \\
\hline Female & 49 & Caucasian & 33.8 & 26.1 & 15.86 & 21.08 & $11.25-28.8$ & $23.83 \%$ & 16.89 & 22.85 & $35.28 \%$ \\
\hline Female & 38 & Caucasian & 32.6 & 27.8 & 19.12 & 22.99 & $11.25-28.8$ & $20.24 \%$ & 20.73 & 25.52 & $23.11 \%$ \\
\hline Female & 37 & Asian & 28.9 & 24.5 & 14.28 & 18.83 & $11.25-28.8$ & $24.16 \%$ & 16.83 & 23.18 & $37.73 \%$ \\
\hline Avera & BMI & ecrease & 32.23 & 26.44 & \multicolumn{3}{|c|}{ Mean Average IGF-1 \% Increase } & $+16.00 \%$ & \multicolumn{2}{|c|}{ Mean Average \% Increase for SMM } & $+23.13 \%$ \\
\hline
\end{tabular}

There was a -5.79 mean average decrease in BMI. Mean average percentage increase of IGF-1 was $+16 \%$. IGF- 1 , remained within the normal range. Mean average percentage increase for skeletal muscle mass was $+23.13 \%$.

Table 3. Blood Plasma Results on VLDL and Triglycerides for each subject.

\begin{tabular}{|c|c|c|c|c|c|c|c|c|c|c|}
\hline Gender & Age & Ethnicity & $\begin{array}{l}\text { Trigly cerides } \\
\text { Pre }(\mathrm{mmol} / \mathrm{l})\end{array}$ & $\begin{array}{l}\text { Trigly cerides } \\
\text { Post }(\mathrm{mmol} / \mathrm{l})\end{array}$ & $\begin{array}{l}\text { Normal range } \\
(\mathrm{mmol} / \mathrm{l})\end{array}$ & $\begin{array}{c}\% \\
\text { decrease }\end{array}$ & $\begin{array}{l}\text { VLDL Pre } \\
(\mathrm{mmol} / \mathrm{l})\end{array}$ & $\begin{array}{l}\text { VLDL Post } \\
(\mathrm{mmol} / \mathrm{l})\end{array}$ & $\begin{array}{c}\text { Normal } \\
\text { range }(\mathrm{mmol} / \mathrm{l})\end{array}$ & $\begin{array}{c}\% \\
\text { decrease }\end{array}$ \\
\hline Male & 36 & Asian & 3.87 & 1.56 & $<1.7$ & $59.68 \%$ & 3.18 & 1.24 & $<1.6$ & $61 \%$ \\
\hline Male & 39 & Caucasian & 3.96 & 1.24 & $<1.7$ & $68.68 \%$ & 3.79 & 1.64 & $<1.6$ & $56.72 \%$ \\
\hline Male & 43 & Caucasian & 3.98 & 1.59 & $<1.7$ & $60 \%$ & 2.98 & 1.39 & $<1.6$ & $53.35 \%$ \\
\hline Male & 35 & Asian & 2.88 & 1.12 & $<1.7$ & $61.11 \%$ & 2.43 & 1.12 & $<1.6$ & $53.90 \%$ \\
\hline Female & 42 & Asian & 2.64 & 0.98 & $<1.7$ & $62.87 \%$ & 3.21 & 1.45 & $<1.6$ & $54.82 \%$ \\
\hline Female & 45 & Indian & 3.23 & 1.64 & $<1.7$ & $49.22 \%$ & 2.86 & 1.16 & $<1.6$ & $59.44 \%$ \\
\hline Female & 49 & Caucasian & 2.45 & 0.93 & $<1.7$ & $62 \%$ & 2.61 & 1.52 & $<1.6$ & $41.76 \%$ \\
\hline Female & 38 & Caucasian & 3.10 & 1.44 & $<1.7$ & $53.54 \%$ & 3.22 & 1.87 & $<1.6$ & $41.92 \%$ \\
\hline Female & 37 & Asian & 2.99 & 1.64 & $<1.7$ & $45.15 \%$ & 2.94 & 0.93 & $<1.6$ & $68.36 \%$ \\
\hline \multicolumn{6}{|c|}{ Mean Average Triglycerides Decrease } & $-58.03 \%$ & \multicolumn{3}{|c|}{ Mean Average VLDL Decrease } & $-54.59 \%$ \\
\hline
\end{tabular}

The average triglycerides and VLDL decreases were consistently analogous with values of $-58.03 \%$ and $-54.59 \%$ respectively.

A close inspection of Table 5 indicates that around $55 \%$ of the subjects were hypothyroid. This was not evident during their medical interview and, apparently the subjects were not aware of having a hypothyroid condition which could be suggestive of prediabetes. We did not test for blood glucose or insulin; therefore, we could not confirm such a hypothesis. However, we recommended that these subjects check their glucose and insulin levels with their primary physicians. The subjects that indicated a hypothyroid condition by their Free T3 being below the normal range, evidenced the greatest increase of Free T3, which however did not spike above normality. Visceral fat decrease had a $t=-9.302125$ and a value of $\mathrm{p}<0.00001$ which brought the statistical significance to $\mathrm{p}<0.00001$. 
The Free $\mathrm{T} 3 \mathrm{t}=29.428273$ with a value of $\mathrm{p}<0.00001$ and a statistical significance level at $\mathrm{p}<0.00001$. Table 6 displays the leptin and ghrelin fluctuations for each subject before and after the treatments. Leptin consistently increased, while ghrelin decreased after the fifteen treatments, for all subjects. Mean average leptin increase was $+10.82 \%$ and mean average ghrelin decrease was -7.35 .

The Analysis of Variance (Table 7) yielded statistically significant results for all variables. All hormones' values were significant but without spiking outside the normal range.

All subjects experienced the procedures as a series of strenuous, yet, effortless exercises. They stated that the technology took control of their bodies, vigorously

Table 4. T-tests statistical significance results on blood plasma and measurement variables.

\begin{tabular}{|c|c|c|c|c|c|c|c|}
\hline & Mean & $\mathrm{S}^{2}=\mathrm{SS} / \mathrm{df}$ & $\mathrm{S} 2 M=\mathrm{S} 2 / \mathrm{N}$ & $\mathrm{SM}=\sqrt{ } \mathrm{S} 2 \mathrm{M}$ & T Value & p Value & Probability \\
\hline VLDL & -1.66 & 0.13 & 0.01 & 0.12 & -14.04 & $<0.00001$ & $\mathrm{P}<0.00001$ \\
\hline Free T-3 & 1.75 & 0.03 & 0.00 & 0.06 & 29.43 & $<0.00001$ & $\mathrm{P}<0.00001$ \\
\hline Leptin & 0.78 & 0.16 & 0.02 & 0.13 & 5.93 & 0.00018 & $\mathrm{P}<0.001$ \\
\hline Ghrelin & -45.89 & 309.61 & 34.4 & 5.87 & -7.82 & 0.00003 & $\mathrm{P}<0.0001$ \\
\hline Cortisol & -25 & 157.25 & 17.47 & 4.18 & -5.98 & 0.00017 & $\mathrm{P}<0.001$ \\
\hline Testosterone & 1.33 & 1.66 & 0.18 & 0.43 & 3.1 & 0.00732 & $\mathrm{P}<0.01$ \\
\hline BMI & -5.79 & 2.52 & 0.28 & 0.53 & -10.94 & $<0.00001$ & $\mathrm{P}<0.00001$ \\
\hline Skeletal Muscle Mass(SMM) & 5 & 1.4 & 0.16 & 0.39 & 12.67 & $<0.00001$ & $\mathrm{P}<0.00001$ \\
\hline IGF-1 & 3.64 & 2.06 & 0.23 & 0.48 & 7.61 & 0.00003 & $\mathrm{P}<0.0001$ \\
\hline
\end{tabular}

Table 5. Scale Results on Visceral Adipose Tissue and Blood Plasma Results on Free T3 for each subject.

\begin{tabular}{|c|c|c|c|c|c|c|c|c|c|}
\hline Gender & Age & Ethnicity & $\begin{array}{l}\text { Visceral } \\
\text { Fat Pre }\end{array}$ & $\begin{array}{l}\text { Visceral } \\
\text { Fat Post }\end{array}$ & $\begin{array}{c}\text { Visceral Fat \% } \\
\text { Decrease }\end{array}$ & $\begin{array}{c}\text { Free T3 } \\
\text { Pre }(\mathrm{nmol} / \mathrm{L})\end{array}$ & $\begin{array}{c}\text { Free T3 } \\
\text { Post }(\mathrm{nmol} / \mathrm{L})\end{array}$ & $\begin{array}{l}\text { Normal } \\
\text { Range } \\
(\mathrm{nmol} / \mathrm{L})\end{array}$ & $\begin{array}{c}\text { Free T3 } \\
\% \text { Increase } \\
(\mathrm{nmol} / \mathrm{L})\end{array}$ \\
\hline Male & 36 & Asian & 128.97 & 113.14 & $12.27 \%$ & 2.56 & 4.29 & $2.63-5.7$ & $67.5 \%$ \\
\hline Male & 39 & Caucasian & 131.20 & 98.53 & $24.9 \%$ & 2.69 & 4.65 & $2.63-5.7$ & $72.86 \%$ \\
\hline Male & 35 & Asian & 99.56 & 79.34 & $20.22 \%$ & 3.56 & 5.31 & $2.63-5.7$ & $49.15 \%$ \\
\hline Female & 42 & Asian & 121.68 & 104.29 & $14.29 \%$ & 2.15 & 3.86 & $2.63-5.7$ & $79.53 \%$ \\
\hline Female & 45 & Indian & 129.73 & 109.28 & $15.76 \%$ & 2.29 & 4.12 & $2.63-5.7$ & $79.9 \%$ \\
\hline Female & 49 & Caucasian & 109.63 & 95.85 & $12.56 \%$ & 2.96 & 4.87 & $2.63-5.7$ & $64.52 \%$ \\
\hline Female & 38 & Caucasian & 122.66 & 87.85 & $28.38 \%$ & 2.54 & 4.20 & $2.63-5.7$ & $65.35 \%$ \\
\hline Female & 37 & Asian & 134.64 & 112.80 & $16.22 \%$ & 1.99 & 3.83 & $2.63-5.7$ & $92.46 \%$ \\
\hline \multicolumn{5}{|c|}{ Mean Average Visceral Fat \% Decrease } & $-18.21 \%$ & \multicolumn{3}{|c|}{ Mean Average Free T3 \% increase } & $+68.81 \%$ \\
\hline
\end{tabular}

Average percentage decrease of visceral adipose tissue was $-18.21 \%$ Average percentage decrease of Free T3 was $+68.81 \%$ 
Table 6. Blood Plasma Results on Leptin and Ghrelin for each subject.

\begin{tabular}{|c|c|c|c|c|c|c|c|c|c|c|}
\hline Gender & Age & Ethnicity & $\begin{array}{l}\text { Leptin pre } \\
\mathrm{ng} / \mathrm{mL}\end{array}$ & $\begin{array}{l}\text { Leptin post } \\
\mathrm{ng} / \mathrm{mL}\end{array}$ & $\begin{array}{l}\text { Normal range } \\
\mathrm{ng} / \mathrm{mL}\end{array}$ & $\begin{array}{c}\% \text { increase } \\
\mathrm{ng} / \mathrm{mL}\end{array}$ & $\begin{array}{c}\text { Ghrelin pre } \\
\text { pg/mL }\end{array}$ & $\begin{array}{l}\text { Ghrelin post } \\
\mathrm{pg} / \mathrm{mL}\end{array}$ & $\begin{array}{c}\text { Normal range } \\
\mathrm{pg} / \mathrm{mL}\end{array}$ & $\begin{array}{c}\% \text { decrease } \\
\mathrm{pg} / \mathrm{mL}\end{array}$ \\
\hline Male & 36 & Asian & 3.69 & 3.98 & $1.2-9.5$ & $7.86 \%$ & 687 & 602 & $520-700$ & $12.37 \%$ \\
\hline Male & 39 & Caucasian & 4.43 & 4.98 & $1.2-9.5$ & $9.78 \%$ & 695 & 634 & $520-700$ & $8.77 \%$ \\
\hline Male & 43 & Caucasian & 5.62 & 6.22 & $1.2-9.5$ & $10.68 \%$ & 598 & 552 & $520-700$ & $7.69 \%$ \\
\hline Male & 35 & Asian & 6.15 & 6.83 & $1.2-9.5$ & $11.05 \%$ & 629 & 587 & $520-700$ & $6.68 \%$ \\
\hline Female & 42 & Asian & 9.16 & 9.74 & $4.1-25.0$ & $6.33 \%$ & 577 & 542 & $520-700$ & $6.06 \%$ \\
\hline Female & 45 & Indian & 5.23 & 6.09 & $4.1-25.0$ & $16.44 \%$ & 659 & 613 & $520-700$ & $6.99 \%$ \\
\hline Female & 49 & Caucasian & 7.22 & 8.17 & $4.1-25.0$ & $13.15 \%$ & 644 & 617 & $520-700$ & $4.19 \%$ \\
\hline Female & 38 & Caucasian & 12.34 & 13.22 & $4.1-25.0$ & $7.13 \%$ & 569 & 536 & $520-700$ & $5.79 \%$ \\
\hline Female & 37 & Asian & 11.38 & 13.08 & $4.1-25.0$ & $14.93 \%$ & 499 & 461 & $520-700$ & $7.62 \%$ \\
\hline \multicolumn{6}{|c|}{ Mean Average Leptin Increase } & $+10.82 \%$ & \multicolumn{3}{|c|}{ Mean Average Ghrelin Decrease } & $-7.35 \%$ \\
\hline
\end{tabular}

There was an inverse relationship between leptin and ghrelin where leptin significantly increased and ghrelin significantly decreased within the normal range. Mean average percentage leptin increase was $+10.82 \%$ and ghrelin decrease was $-7.35 \%$.

Table 7. Analysis of variance statistical significance results on blood plasma and measurement variables.

\begin{tabular}{|c|c|c|c|c|c|c|}
\hline & SS & df & MS & F-Ratio Value & p-Value & Significance Level \\
\hline & BT: $242,251.2736$ & BT:3 & BT: $80,750.4245$ & & & \\
\hline \multirow[t]{3}{*}{ Testosterone Cortisol } & WT: 25,503.9549 & WT:32 & WT: 796.9986 & $F=136.51681$ & $<0.00001$ & $\mathrm{P}<0.00001$ \\
\hline & E: $14,196.1284$ & $\mathrm{E}: 24$ & E: 591.5053 & & & \\
\hline & BT: 251.7344 & BT:3 & BT: 83.9115 & & & \\
\hline \multirow[t]{3}{*}{ IGF-1/SMM } & WT: 1167.9813 & WT:32 & WT: 36.4994 & $\mathrm{~F}=16.33532$ & $<0.00001$ & $\mathrm{P}<0.00001$ \\
\hline & E: 123.2835 & E:24 & E: 5.1368 & & & \\
\hline & BT: 28.34943 & BT:3 & BT: 9.4648 & & & \\
\hline \multirow[t]{3}{*}{ VLDL / Triglycerides } & WT: 5.2282 & WT:32 & WT: 0.16434 & $\mathrm{~F}=81.45242$ & $<0.00001$ & $\mathrm{P}<0.00001$ \\
\hline & E: 2.7888 & $\mathrm{E}: 24$ & E: 0.1162 & & & \\
\hline & BT: $105,989.285$ & BT:3 & BT: $35,328.4283$ & & & \\
\hline \multirow[t]{3}{*}{ Visceral Fat Free T3 } & WT: 2064.6557 & WT:32 & WT: 64.5205 & $F=704.83951$ & $<0.00001$ & $\mathrm{P}<0.00001$ \\
\hline & E: 1202.9437 & E:24 & E: 50.1227 & & & \\
\hline & BT: $3,100,114.916$ & BT:3 & BT: $1,036,371.6387$ & & & \\
\hline \multirow[t]{2}{*}{ Leptin Ghrelin } & WT: 55,563.1985 & WT:32 & WT: 1736.35 & $F=804.2602$ & $<0.00001$ & $\mathrm{P}<0.00001$ \\
\hline & E: $30,926.4581$ & E:24 & E: 1288.6024 & & & \\
\hline
\end{tabular}

Abbreviations: BT: Between Treatments/WT: Within Treatments/E: Error.

contracting their entire musculature, then shaking and twisting their muscles in circular coordinated motions, as if they were performing gymnastics, but without the muscle aches and tiredness following an intense workout. They also reported reduced cravings for chocolate, snacks, fried foods and carbohydrates, and were excited by the idea of buying new, smaller size clothes.

In both of their interviews, after the last treatment, and two weeks later, the subjects consistently reported enhanced fitness and energy. 


\section{Discussions}

The primary goal of this randomized double blind clinical trial was to bring attention to the systemic balance perspective of health maintenance. Deterioration into illness is gradual. It evolves out of minor dysregulations, inconspicuously disintegrating the structure of wellness. Hormonal levels within the normal range are widely accepted as optimum, without examining the actual ranking position that enables each variable defend or undermine health. Cortisol rising towards the peak of the normal range can easily spiral out of control, and Free T3 close to the bottom may signify the insidious onset of hypothyroidism. A preventive perspective focuses on the rate of differentiation, observing the degrees of minor imbalances within normalcy, before they are exacerbated into a medical disorder. This is necessary to safeguard a biological network in flux. Variations within the normal range can be utilized to estimate both health improvement and the probability of illness vulnerability.

An equally important objective was to examine whether an alternative to exercise can reduce BMI, and improve the health of overweight individuals, possibly decreasing their susceptibility to medical disorders or viral infections. All subjects indicated a BMI decrease after the fifteen treatments. There was evidence that visceral adiposity, VLDL and triglycerides were reduced, accompanied by increased metabolism, and an optimal leptin/ghrelin inverse relationship, indicating that this method can serve as a proactive/preventive and possibly corrective measure to counteract the adverse effects of obesity. The substantial IGF-1 and skeletal muscle mass enhancement implied enhanced fitness. Using this method as an alternative to exercise can be both practical and convenient at a time when an active lifestyle is limited due to the COVID-19 pandemic. But even without the COVID-19 confinement and social distancing, an alternative to exercise can be beneficial in maintaining wellness. Usually, work responsibilities and socioeconomic demands take precedence over engaging in sports. Physical activity becomes more laborious and cumbersome with age, hence the accumulation of visceral fat along with its inherent inflammation, lipids and lipoproteins, and the greater vulnerability to decease during aging. Offering a fast solution that can produce a visible physique change, and improve health within five weeks, has significant implications in safeguarding immunity.

Although physical training is necessary for cardiovascular health, strenuous exercise increases cortisol, reinforcing stress eating behaviours, while reducing testosterone that is clinically associated with a number of medical and mental conditions. Low testosterone levels are prominent in diabetics, and they are correlated with a prolonged depressive disorder in elderly males, often expressed in terms of low energy, anhedonia, appetite disturbances, hopelessness and sexual dysfunction [59] [60]. Our sample evidenced the opposite: an optimal inverse testosterone/cortisol relationship, where testosterone climbed towards the peak of the normal range and cortisol decreased but without dipping into abnormality. Our subjects reported reduced cravings for sugar and fatty foods, yet, normal 
appetite, possibly signifying a combination of optimal cortisol levels, combined with adequate modulation of central inhibitors and stimulators of appetite such as leptin and ghrelin respectively.

The current clinical trial has numerous methodological limitations. Firstly, the small sample size, and the absence of imaging techniques that were beyond our research budget, since we received no financial aid from an outside source. We assessed visceral fat and skeletal muscle mass on the basis of a conductance scale, the results of which are not widely recognized as reliable, despite their common use by a large body of research. We did not compare our sample to a control exercise group, or a placebo group. In previous research, eight weeks of exercise showed a modest reduction of visceral fat, but without a clinically significant weight loss [61]. Another computer tomography scan based study found no differences in BMI or physical fitness [62]. The alternative to exercise adopted in this clinical trial, showed a statistically significant decrease in BMI and an increase in skeletal muscle mass after only five weeks of treatment. Still, including an exercise control group, in compliance with established research principles, would increase the validity of our study. Subjects were only followed for two weeks, during which time they maintained the results they achieved without rebound. However, a longitudinal study is necessary to confirm results durability, and establish that the health enhancement observed with this diverse population is, in fact, effective in eventually preventing the likelihood of disease or a viral infection. Lastly, we did not include other important weight variables such as basal metabolic rate (BMR), $\mathrm{cm}$ loss, and $\mathrm{kg}$, as a result of inconsistency of these measurements in the data collected from the five clinics. Conducting a longitudinal study with a larger sample and more variables is necessary to validate the current findings.

\section{Acknowledgements}

The author received no funding for this research project. The author would like to thank Dr Gerald Pollock and Dr Donald Gibson, both deceased, for their London University invention used in this clinical trial. Additionally, she would like to thank the doctors of the five clinics who offered the data included in this study.

\section{Conflicts of Interest}

The author declares no conflicts of interest regarding the publication of this paper.

\section{References}

[1] Dixon, A.E. and Peters, U. (2018) The Effect of Obesity on Lung Function. Expert Review of Respiratory Medicine, 12, 755-767. https://doi.org/10.1080/17476348.2018.1506331

[2] Al-Goblan, A.S., Al-Alfi, M.A. and Khan, M.Z. (2014) Mechanism Linking Diabetes Mellitus and Obesity. Diabetes, Metabolic Syndrome and Obesity: Targets and Ther- 
apy, 7, 587-591. https://doi.org/10.2147/DMSO.S67400

[3] Després, J. and Lemieux, I. (2006) Abdominal Obesity and Metabolic Syndrome. Nature, 444, 881-887. https://doi.org/10.1038/nature05488

[4] Larsson, B., Svärdsudd, K., Welin, L., Wilhelmsen, L., Björntorp, P. and Tibblin, G. (1984) Abdominal Adipose Tissue Distribution, Obesity, and Risk of Cardiovascular Disease and Death: 13 Year Follow up of Participants in the Study of Men Born in 1913. British Medical Journal (Clinical Research Ed.), 288, 1401-1404. https://doi.org/10.1136/bmj.288.6428.1401

[5] Rabkin, S.W. and Mathewson, F.A. (1977) Hsu PH: Relation of Body Weight to Development of Ischemic Heart Disease in a Cohort of Young North American Men after a 26 Year Observation Period: the Manitoba Study. The American Journal of Cardiology, 39, 452-458. https://doi.org/10.1016/S0002-9149(77)80104-5

[6] Odegaard, A.O., Koh, W. P., Vazquez, G., Arakawa, K., Lee, H.P., Mimi, C.Y. and Pereira, M.A. (2009) BMI and Diabetes Risk in Singaporean Chinese. Diabetes Care, 32, 1104-1106. https://doi.org/10.2337/dc08-1674

[7] Resnick, H.E., Valsania, P., Halter, J.B. and Lin, X. (1998) Differential Effects of BMI on Diabetes Risk among Black and White Americans. Diabetes Care, 21, 1828-1835. https://doi.org/10.2337/diacare.21.11.1828

[8] Resnick, H.E., Valsania, P., Halter, J.B. and Lin, X. (1998) Relation of Weight Gain and Weight Loss on Subsequent Diabetes Risk in Overweight Adults. Journal of Epidemiology \& Community Health, 54, 596-602. https://doi.org/10.1136/jech.54.8.596

[9] Peng, Y.D., Meng, K, Guan, H.Q., et al. (2020) Clinical Characteristics and Outcomes of 112 Cardiovascular Disease Patients Infected by 2019-nCoV. Chinese Journal of Cardiovascular Diseases, 48, E004.

[10] Jia, X., Yin, C., Lu, S., Chen, Y., Liu, Q., Bai, J. and Lu, Y. (2020) Two Things about COVID-19 Might Need Attention. Preprints, 2020020315. https://doi.org/10.20944/preprints202002.0315.v1

[11] Hoffmann, M., Kleine-Weber, H., Schroeder, S., et al. (2020) SARS-CoV-2 Cell Entry Depends on ACE2 and TMPRSS2 and Is Blocked by a Clinically Proven Protease Inhibitor. Cell, 181, 271-280.E8. https://www.sciencedirect.com/science/article/pii/S0092867420302294

[12] Ira Martin, G and Sowers, J.R. (2014) Thyroid and the Heart. The American Journal of Medicine, 127, 691-698. https://www.ncbi.nlm.nih.gov/pmc/articles/PMC4318631

[13] Perros, P., Mccrimmon R.J., Shaw G. and Frier, B.M. (1995) Frequency of Thyroid Dysfunction in Diabetic Patients: Value of Annual Screening. Diabetic Medicine, 12, 622-627. https://www.ncbi.nlm.nih.gov/pubmed/7554786

[14] Dundas, L.H., Orgiazzi, J. and Brabant, G. (2011) The Interface between Thyroid and Diabetes Mellitus. Clinical Endocrinology, 75, 1-9. https://www.ncbi.nlm.nih.gov/pubmed/21521298

[15] Nirosha, K., Divya, M., Vamsi, S. and Sadiq, M. (2014) A Review on Hyperlipidemia. International Journal of Novel Trends in Pharmaceutical Sciences, 4, 81-92. https://scienztech.org/ijntps/article/view/112

[16] Ren, J., Grundy, S.M., Liu, J., Wang, W., Wang, M., Sun, J., Li, Y., Wu, Z. and Zhao, D. (2010) Long-Term Coronary Heart Disease Risk Associated with Very-Low-Density Lipoprotein Cholesterol in Chinese: The Results of a 15-Year Chinese Multi-Provincial Cohort Study (CMCS). Atherosclerosis, 211, 327-332. 
https://doi.org/10.1016/j.atherosclerosis.2010.02.020

[17] Ginsberg HN. (1987) Very Low Density Lipoprotein Metabolism in Diabetes Mellitus. Diabetes/Metabolism Reviews, 3, 571-589.

https://www.ncbi.nlm.nih.gov/pubmed/3552533

[18] Whitworth, J.A., Williamson, P.M., Mangos, G. and Kelly, J.J. (2005) Cardiovascular Consequences of Cortisol Excess. Vascular Health and Risk Management, 1, 291-299. https://doi.org/10.2147/vhrm.2005.1.4.291

[19] Chiodini, I., Adda, G., Scillitani, A., Coletti, F., Morelli, V., Di Lembo, S. and Ambrosi, B. (2007) Cortisol Secretion in Patients with Type 2 Diabetes: Relationship with Chronic Complications. Diabetes Care, 30, 83-88. https://doi.org/10.2337/dc06-1267

[20] Kelly, J.J., Mangos, G., Williamson, P.M. and Whitworth, J.A. (1998) Cortisol and Hypertension. Clinical and Experimental Pharmacology and Physiology, 25, S51-S56. https://doi.org/10.1111/j.1440-1681.1998.tb02301.x

[21] George, S.A., Khan, S., Briggs, H. and Abelson, J.L. (2010) CRH-Stimulated Cortisol Release and Food Intake in Healthy, Non-Obese Adults. Psychoneuroendocrinology, 35, 607-612. https://doi.org/10.1016/j.psyneuen.2009.09.017

[22] Hyman, M. (2005) Systems Biology, Toxins, Obesity, and Functional Medicine. The Proceedings from the 13 th International Symposium of the Institute for Functional Medicine Managing Biotransformation: The Metabolic, Genomic, and Detoxification Balance Points, S134-139.

http://www.alternative-therapies.com/at/web_pdfs/ifm_proceedings_low.pdf

[23] Abdemur, A., Slone, J., Berho, M., Gianos, M., Szomstein, S. and Rosenthal, R.J. (2014) Morphology, Localization, and Patterns of Ghrelin-Producing Cells in Stomachs of a Morbidly Obese Population. Surgical Laparoscopy Endoscopy \& Percutaneous Techniques, 24, 122-126. https://pubmed.ncbi.nlm.nih.gov/24686346/

[24] Zakrzewska, K.E., Cusin, I., Sainsbury, A., Rohner-Jeanrenaud, F. and Jeanrenaud, B. (1997) Glucocorticoids as Counterregulatory Hormones of Leptin: Toward an Understanding of Leptin Resistance. Diabetes, 46, 717-719. https://pubmed.ncbi.nlm.nih.gov/9075817/

[25] Banks, W.A. (2012) Role of the Blood-Brain Barrier in the Evolution of Feeding and Cognition. Annals of the New York Academy of Sciences, 1264, 13-19.

https://www.ncbi.nlm.nih.gov/pmc/articles/PMC3464352/

[26] Correia, M.L. and Haynes, WG. (2004) Leptin, Obesity and Cardiovascular Disease. Current Opinion in Nephrology and Hypertension, 13, 215-223. https://pubmed.ncbi.nlm.nih.gov/15202616/.

[27] Alti, D., Sambamurthy, C. and Kalangi, S.K. (2018) Emergence of Leptin in Infection and Immunity: Scope and Challenges in Vaccines Formulation. Frontiers in Cellular and Infection Microbiology, 8, 147. https://www.ncbi.nlm.nih.gov/pmc/articles/PMC5954041/

[28] Ceddia, R., William, W. and Curi, R. (1999) Comparing Effects of Leptin and Insulin on Glucose Metabolism in Skeletal Muscle: Evidence for an Effect of Leptin on Glucose Uptake and Decarboxylation. International Journal of Obesity, 23, 75-82. https://doi.org/10.1038/sj.ijo.0800762

[29] O’Rourke, L., Gronning, L.M., Yeaman, S.J. and Shepherd, P.R. (2002) Glucose-Dependent Regulation of Cholesterol Ester Metabolism in Macrophages by Insulin and Leptin. Journal of Biological Chemistry, 277, 42557-42562. https://pubmed.ncbi.nlm.nih.gov/12200416/ 
[30] Park, H.-K. and Ahima, R.S. (2015) Physiology of Leptin: Energy Homeostasis Neuroendocrine Function and Metabolism. Metabolism, 64, 24-34. https://www.sciencedirect.com/science/article/abs/pii/S0026049514002418

[31] Gupta, R., Ghosh, A., Singh, A.K. and Misra, A. (2020) Clinical Considerations for Patients with Diabetes in Times of COVID-19 Epidemic. Diabetes \& Metabolic Syndrome: Clinical Research \& Reviews, 14, 211-212. https://doi.org/10.1016/j.dsx.2020.03.002

[32] Johnson, T.A., Jinnah, H.A. and Kamatani, N. (2019) Shortage of Cellular ATP as a Cause of Diseases and Strategies to Enhance ATP. Frontiers in Pharmacology, 10, 98. https://doi.org/10.3389/fphar.2019.00098

[33] de Wit, E., van Doremalen, N., Falzarano, D., et al. (2016) SARS and MERS: Recent Insights into Emerging Coronaviruses. Nature Reviews Microbiology, 14, 523-534. https://www.nature.com/articles/nrmicro.2016.81.pdf?origin = ppub

[34] Channappanavar, R., Fehr, A.R., Vijay, R. Mack, M., Zhao, J., Meyerholz, D.K., et al. (2016) Dysregulated Type I Interferon and Inflammatory Monocyte-Macrophage Responses Cause Lethal Pneumonia in SARS-CoV-Infected Mice. Cell Host \& Microbe, 19, 181-193. https://doi.org/10.1016/j.chom.2016.01.007

[35] Thevarajan, I., Nguyen, T.H.O., Koutsakos, M., et al. (2020) Breadth of Concomitant Immune Responses Prior to Patient Recovery: A Case Report of Non-Severe COVID-19. Nature Medicine, 26, 453-455. https://doi.org/10.1038/s41591-020-0819-2

[36] Taghizadeh-Hesary, F. and Ahbari, H. (2020) The Powerful Immune System against Powerful COVID-19: A Hypothesis. Medical Hypotheses, 140, Article ID: 109762. https://doi.org/10.1016/j.mehy.2020.109762

[37] Zhang, C., He, H., Wang, L., Zhang, N., Huang, H., Xiong, Q., et al. (2017) Virus-Triggered ATP Release Limits Viral Replication through Facilitating IFN- $\beta$ Production in a P2X7-Dependent Manner. The Journal of Immunology, 199, 1372-1381. https://doi.org/10.4049/jimmunol.1700187

[38] Wu, Z. and McGoogan, J.M. (2020) Characteristics of and Important Lessons from the Coronavirus Disease 2019 (COVID-19) Outbreak in China: Summary of a Report of 72314 Cases from the Chinese Center for Disease Control and Prevention. JAMA, 323 1239-1242. https://doi.org/10.1001/jama.2020.2648

[39] Qian, F., Wang, X., Zhang, L., Lin, A., Zhao, H., Fikrig, E. and Montgomery, R.R. (2011) Impaired Interferon Signaling in Dendritic Cells from Older Donors Infected in Vitro with West Nile Virus. Journal of Infectious Diseases, 203, 1415-1424. https://doi.org/10.1093/infdis/jir048

[40] Burelle, Y. and Hochachka, P.W. (2002) Endurance Training Induces Muscle-Specific Changes in Mitochondrial Function in Skinned Muscle Fibers. Journal of Applied Physiology, 92, 2429-2438. https://doi.org/10.1152/japplphysiol.01024.2001

[41] Malińska, D., Więckowski, M.R., Michalska, B., Drabik, K., Prill, M., Patalas-Krawczyk, P., Luettich, K., et al. (2019) Mitochondria as a Possible Target for Nicotine Action. Journal of Bioenergetics and Biomembranes, 51, 259-276. https://doi.org/10.1007/s10863-019-09800-Z

[42] Perl, A., Gergely Jr., P., Nagy, G., Koncz, A. and Banki, K. (2004) Mitochondrial Hyperpolarization: A Checkpoint of T-Cell Life, Death and Autoimmunity. Trends in Immunology, 25, 360-367. https://doi.org/10.1016/j.it.2004.05.001

[43] Kassi, E. and Moutsatsou, P. (2010) Estrogen Receptor Signaling and Its Relationship to Cytokines in Systemic Lupus Erythematosus. Journal of Biomedicine and Biotechnology, 2010, Article ID: 317452 https://doi.org/10.1155/2010/317452 
[44] Ruan, Q., Yang, K., Wang, W., Jiang, L. and Song, J. (2020) Clinical Predictors of Mortality Due to COVID-19 Based on an Analysis of Data of 150 Patients from Wuhan, China. Intensive Care Medicine, 46, 846-848. https://doi.org/10.1007/s00134-020-05991-x

[45] Zhou, F., Yu, T., Du, R., Fan, G., Liu, Y., Liu, Z., Xiang, J., Wang, Y., Song, B., Gu, X., Guan, L., Wei, Y., Li, H., Wu, X., Xu, J., Tu, S., Zhang, Y., Chen, H. and Cao, B. (2020) Clinical Course and Risk Factors for Mortality of Adult Inpatients with COVID-19 in Wuhan, China: A Retrospective Cohort Study. The Lancet, 395, 1054-1062. https://www.ncbi.nlm.nih.gov/pubmed/32171076.

[46] Kirby, M., Hackett, G. and Ramachandran, S. (2019) Testosterone and the Heart. European Cardiology Review, 14, 103-110. https://doi.org/10.15420/ecr.2019.13.1

[47] Rowland, S.P. and O’Brien Bergin, E. (2020) Screening for Low Testosterone Is Needed for Early Identification and Treatment of Men at High Risk of Mortality from Covid-19. Critical Care, Article No. 24, 367. https://doi.org/10.1186/s13054-020-03086-Z

[48] Roser, M., Ritchie, H., Ortiz-Ospina, E. and Hasell, J. (2020) Coronavirus Pandemic (COVID-19). Our World in Data. https://ourworldindata.org/coronavirus

[49] Lavie, C.J., Ozemek, C., Carbone, S., Katzmarzyk, P.T. and Blair, S.N. (2019) Sedentary Behavior, Exercise, and Cardiovascular Health. Circulation Research, 124, 799-815. https://doi.org/10.1161/CIRCRESAHA.118.312669

[50] Kaminsky, L.A., Arena, R., Ellingsen, Ø., Harber, M.P., Myers, J., Ozemek, C. and Ross, R. (2019) Cardiorespiratory Fitness and Cardiovascular Disease-The Past, Present, and Future. Progress in Cardiovascular Diseases, 62, 86-93. https://doi.org/10.1016/j.pcad.2019.01.002

[51] Imboden, M.T., Harber, M.P., Whaley, M.H., Finch, W.H., Bishop, D.L., Fleenor, B.S. and Kaminsky, L.A. (2019) The Association between the Change in Directly Measured Cardiorespiratory Fitness across Time and Mortality Risk. Progress in Cardiovascular Diseases, 62, 157-162. https://www.ncbi.nlm.nih.gov/pubmed/30543812

[52] Ozemek C., Laddu, D.R. and Lavie C.J. (2018) An Update on the Role of Cardiorespiratory Fitness, Structured Exercise and Lifestyle Physical Activity in Preventing Cardiovascular Disease and Health Risk. Progress in Cardiovascular Diseases, 61, 484-490. https://doi.org/10.1016/j.pcad.2018.11.005

[53] Hill, E.E., Zack, E., Battaglini, C., Viru, M., Viru, A. and Hackney, A.C. (2008) Exercise and Circulating Cortisol Levels: The Intensity Threshold Effect. Journal of Endocrinological Investigation, 31, 587-591. https://doi.org/10.1007/BF03345606

[54] Skoluda, N., Dettenborn, L., Stalder, T. and Kirschbaum, C. (2012) Elevated Hair Cortisol Concentrations in Endurance Athletes. Psychoneuroendocrinology, 37, 611-617. https://doi.org/10.1016/j.psyneuen.2011.09.001

[55] Pedersen, B.K., Steensberg, A. and Schjerling, P. (2001) Muscle-Derived Interleukin-6: Possible Biological Effects. The Journal of Physiology, 536, 329-337. https://www.ncbi.nlm.nih.gov/pmc/articles/PMC2278876/

[56] Sofra, X. and Lampe, N. (2020) Empowering the Woman: A Comprehensive Model of Sexual Anti-Aging. Journal of Aesthetic Nursing, 9, 118-127. https://doi.org/10.12968/joan.2020.9.3.118

[57] Sofra, X. (2020) Gain without Pain: Beyond Sport Effortless Exercise Solutions. Journal of Aesthetic Nursing, 9, 202-210. https://doi.org/10.12968/joan.2020.9.5.202

[58] Goldspink, G., Scutt, A., Martindale, J., Jaenicke, T., Turay, L. and Gerlach, G.F. (1991) Stretch and Force Generation Induce Rapid Hypertrophy and Myosin Iso- 
form Gene Switching in Adult Skeletal Muscle. Biochemical Society Transactions, 19, 368-373. https://doi.org/10.1042/bst0190368

[59] Grossmann, M. (2011) Low Testosterone in Men with Type 2 Diabetes: Significance and Treatment. The Journal of Clinical Endocrinology \& Metabolism, 96, 2341-2353. https://doi.org/10.1210/jc.2011-0118

[60] Shores, M.M., Moceri, V.M., Sloan, K.L., Matsumoto, A.M. and Kivlahan, D.R. (2005) Low Testosterone Levels Predict Incident Depressive Illness in Older Men: Effects of Age and Medical Morbidity. The Journal of Clinical Psychiatry, 66, 7-14. https://doi.org/10.4088/JCP.v66n0102

[61] Keating, S., Hackett, D., Parker, H, O’Connor, H., Gerofi, J., Sainsbury, A., Baker, M., Chuter, V., Caterson, I., George, J. and Jhonson, N. (2015) Effect of Aerobic Exercise Training Dose on Liver Fat and Visceral Adiposity. Journal of Hematology, 63, 174-182. https://doi.org/10.1016/j.jhep.2015.02.022

[62] Kim, K., Valentine, R., Shin, Y. and Gong, K. (2008) Associations of Visceral Adiposity and Exercise Participation with C-Reactive Protein, Insulin Resistance, and Endothelial Dysfunction in Korean Healthy Adults. Metabolism, 57, 1181-1189. https://doi.org/10.1016/j.metabol.2008.04.009 